\title{
Synthesis of Sacubitril
}
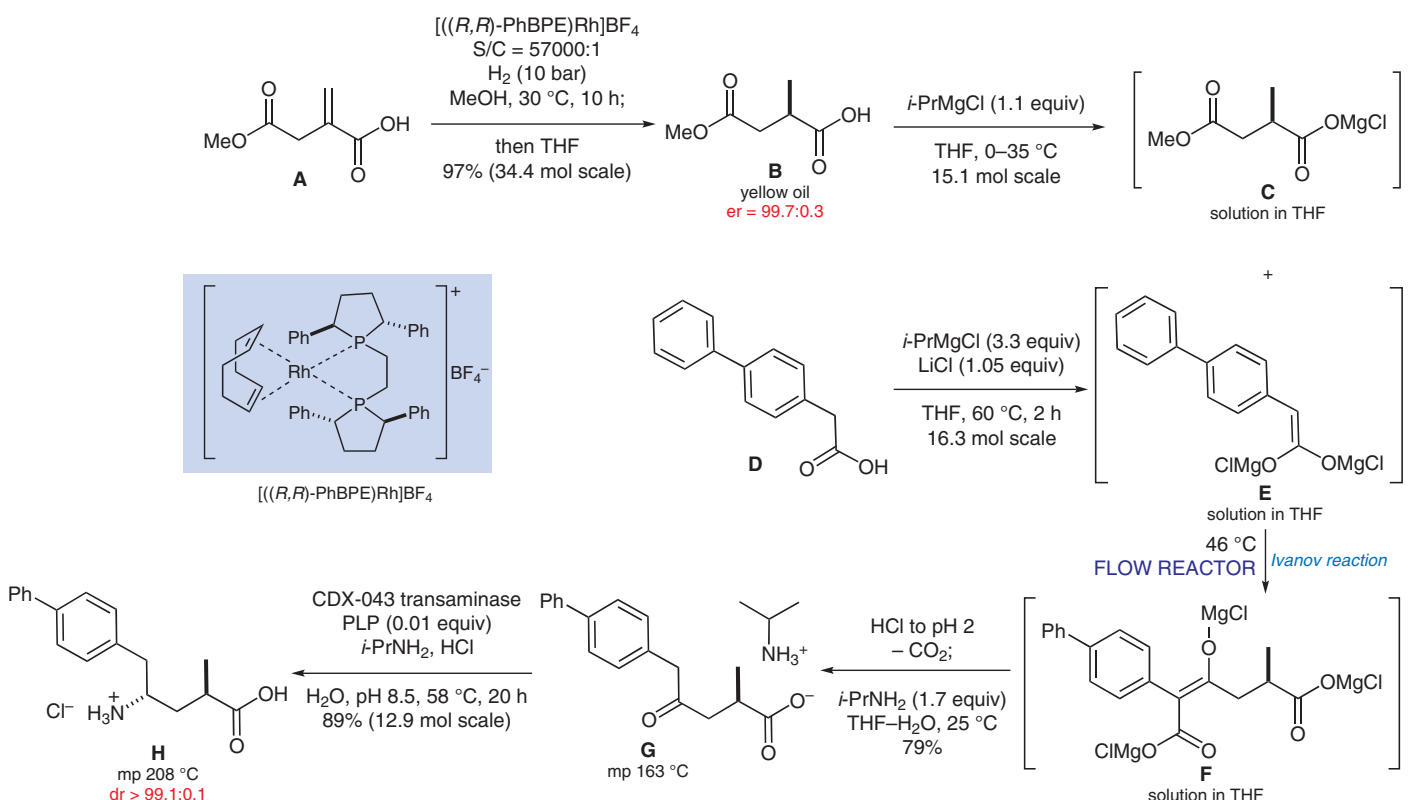

FLOW REACTOR
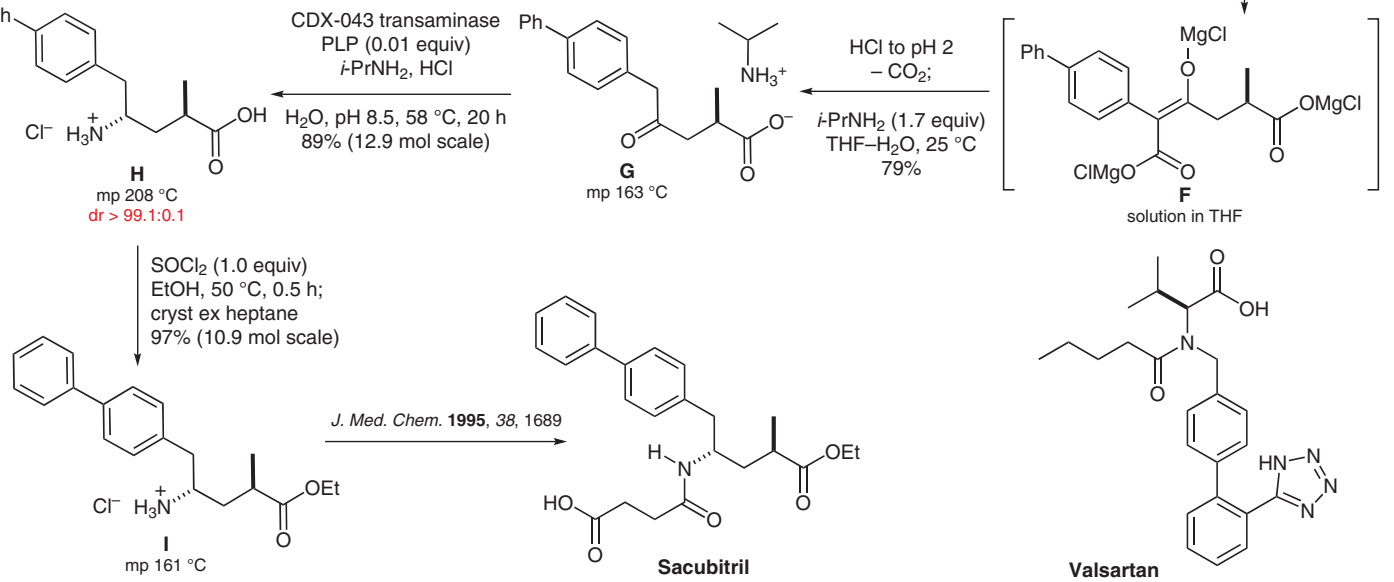

Significance: Sacubitril is a nephrilysin inhibitor used in combination with the angiotensin II inhibitor valsartan. The combination drug (LCZ696), marketed under the brand name Entresto ${ }^{\circledR}$, was approved by the FDA in 2015 for the treatment of heart failure. A noteworthy step in the synthesis of sacubitril depicted features a flow reactor to perform the Ivanov reaction (Synthesis 1975, 83) by which the carboxylic acids $\mathbf{B}$ and $\mathbf{D}$ were condensed to give $\gamma$-ketoacid derivative $\mathbf{G}$ in $79 \%$ yield on a $15.1 \mathrm{~mol}$ scale.

\section{Category}

Synthesis of Natural

Products and

Potential Drugs

\section{Key words}

sacubitril

LCZ696

asymmetric hydrogenation

rhodium catalysis

flow reactor

Ivanov reaction

transaminase
Comment: The $(R, R)$-Ph-BPE-derived rhodium complex in methanol at $30^{\circ} \mathrm{C}$ and a hydrogen pressure of 10 bar provided the best performance among the catalyst systems screened for the asymmetric hydrogenation of $\mathbf{A}$. Complete conversion into $\mathbf{B}$ was observed in concentrations as high as $1.3 \mathrm{~g} / \mathrm{mL}$ and catalyst loadings as low as $\mathrm{S} / \mathrm{C}$ $74,000: 1$, providing the product in high purity and excellent enantioselectivity (er $=99.7: 0.3)$. 